OPEN ACCESS

Edited by:

Natalia V. Kirienko,

Rice University, United States

Reviewed by:

Hamid Badali,

The University of Texas Health

Science Center at San Antonio,

United States

Katherine Simpson Barker,

University of Tennessee Health

Science Center (UTHSC),

United States

*Correspondence: Anshan Shan

asshan@neau.edu.cn Jiajun Wang

wjj1989@neau.edu.cn

Specialty section: This article was submitted to Antimicrobials, Resistance and Chemotherapy,

a section of the journal

Frontiers in Microbiology

Received: 03 April 2020 Accepted: 07 September 2020 Published: 30 September 2020

Citation:

Yang Y, Wang C, Gao N, Lyu Y,

Zhang $L$, Zhang $S$, Wang $J$ and Shan A (2020) A Novel Dual-Targeted

$\alpha$-Helical Peptide With Potent

Antifungal Activity Against Fluconazole-Resistant Candida albicans Clinical Isolates.

Front. Microbiol. 11:548620. doi: 10.3389/fmicb.2020.548620

\section{A Novel Dual-Targeted $\alpha$-Helical Peptide With Potent Antifungal Activity Against Fluconazole-Resistant Candida albicans Clinical Isolates}

\author{
Yang Yang ${ }^{1}$, Chenxi Wang ${ }^{1}$, Nan Gao', Yinfeng Lyu' ${ }^{1}$, Licong Zhang ${ }^{1}$, Sujiang Zhang', \\ Jiajun Wang ${ }^{1 *}$ and Anshan Shan ${ }^{1 *}$
}

\footnotetext{
1 Laboratory of Molecular Nutrition and Immunity, Institute of Animal Nutrition, Northeast Agricultural University, Harbin, China, ${ }^{2}$ Key Laboratory of Tarim Animal Husbandry Science and Technology, College of Animal Science, Tarim University, Alar, China
}

Due to compromised immune system, fungal infection incidences have markedly increased in the last few decades. Pathogenic fungi have developed resistance to the clinically available antifungal agents. Antifungal resistance poses a great challenge to clinical treatment and has stimulated the demand for novel antifungal agents. A promising alternative to the treatment of fungal diseases is the use of antimicrobial peptides (AMPs). However, the antifungal activities of AMPs have not been fully determined. Therefore, this study aimed at designing and screening $\alpha$-helical peptides with potential antifungal activities. The effects of key physicochemical parameters on antifungal activities were also investigated. A series of lengthened and residuesubstituted derivatives of the template peptide $\mathrm{KV}$, a hexapeptide truncated from the $\alpha$-helical region of porcine myeloid antimicrobial peptide-36, were designed and synthesized. Enhancement of hydrophobicity by introducing aromatic hydrophobic amino acids (tryptophan and phenylalanine) significantly increased the efficacies of the peptides against Candida albicans strains, including fluconazole-resistant isolates. Increased hydrophobicity also elevated the toxic properties of these peptides. RF3 with moderate hydrophobicity exhibited potent anticandidal activities $(\mathrm{GM}=6.96 \mu \mathrm{M})$ and modest hemolytic activities $(\mathrm{HC} 10>64 \mu \mathrm{M})$. Additionally, repeated exposure to a subinhibitory concentration of RF3 did not induce resistance development. The antifungal mechanisms of RF3 were due to membrane disruptions and induction of reactive oxygen species production. Such a dual-targeted mechanism was active against drug-resistant fungi. These results show the important role of hydrophobicity and provide new insights into designing and developing antifungal peptides. Meanwhile, the successful design of RF3 highlights the potential utility of AMPs in preventing the spread of drug-resistant fungal infections.

Keywords: antimicrobial peptides, antifungal activity, fluconazole resistance, Candida albicans, membrane disruption, ROS production 


\section{INTRODUCTION}

Antimicrobial resistance (AMR) is a serious public health concern globally. The burden and consequences of antifungal resistance have not been fully recognized (Sanglard, 2016; Fisher et al., 2018). In the past few decades, incidences of fungal infections have increased dramatically due to impaired immune systems, complex surgical procedures, and extensive antibiotic treatment (Andes et al., 2016; Limper et al., 2017; Vazquez, 2017). The Candida species of fungi are frequently encountered as etiological agents of nosocomial infections. Infections due to Candida range from cutaneous to severe invasive infections (Pappas et al., 2004; Fesharaki et al., 2013). The Candida albicans (C. albicans) strain of this species is the most prevalent and is responsible for more than $50 \%$ of human candidiasis cases (Zhang et al., 2015). Despite this prevalence, therapeutic options are limited. Currently, there are three classes of antifungal drugs used to treat severe $C$. albicans infections. They include the azoles, the echinocandins, and the polyenes (Odds et al., 2003; Nett and Andes, 2016). Resistance to first- and second-line antifungals, such as echinocandins and fluconazole (FLU), are a major challenge toward C. albicans infections (Whaley et al., 2016; Bhetariya et al., 2017). Resistance has necessitated efforts toward the development of novel antifungal agents.

The potent, broad-spectrum endogenous antibiotics, antimicrobial peptides (AMPs), have emerged as a rising star in the field of drug research. As an intrinsic part of the innate immune system, AMPs exist widely in nearly all living organisms, providing the first line of defense against a broad range of invading microorganisms (Broekaert et al., 1995; Vos et al., 1995; Ganz and Lehrer, 1998). AMPs have diverse structures, biological functions, and molecular targets. Therefore, a systematic classification of AMPs will improve the efficiency in AMP research. AMPs can be classified into four groups based on their secondary structures, namely, liner $\alpha$-helical peptides, $\beta$ sheet-containing peptides, peptides involving $\alpha$ - and $\beta$-elements, and extended peptides (Koehbach and Craik, 2019). The $\alpha$-helical peptides are the most frequently encountered in nature and have been extensively studied due to their high synthetic accessibility. Alpha-helical peptides share common characteristics that contribute to their biological activities. These characteristics include positive charges, hydrophobicity, and amphiphilicity that disrupt microbial membranes. Upon electrostatic interactions with negatively charged cell membranes, these peptides assume secondary conformations that facilitate the insertion of their hydrophobic regions into the cell membrane (Nguyen et al., 2011; Wang et al., 2019). Moreover, AMPs can also be classified based on their antimicrobial activities. These functions could be antibacterial, antifungal, antiviral, and antiparasitic (Lacerda et al., 2016; Kodedová and Sychrová, 2017; Methatham et al., 2017; Chou et al., 2019). In addition to the ability to fight against microbes, some AMPs exhibit antioxidant, anti-inflammatory, and wound healing properties (Harioudh et al., 2017; Williams et al., 2018; Dou et al., 2019). Studies aimed at improving the antibacterial activities of AMPs and confirming the efficacy of antibacterial peptides designed by sequence modifications from naturally occurring, templated peptides or de novo design of a few amino acids have been done (Shao et al., 2018; Yang et al., 2019, 2020). However, the antifungal activities of the AMPs have only been partially explored. In addition to the earlier mentioned methods of classification, AMPs can be classified into cell membrane- and intracellular-targeting peptides (Lécorché et al., 2012; Li et al., 2017). Three membrane-disrupting mechanisms of AMPs have been proposed. They include barrel-stave, carpet, and toroidal mechanisms (Li et al., 2017). Additionally, many AMPs exhibit antimicrobial effects by interacting with intracellular target molecules (e.g., proteins, DNA, and RNA) or by acting as metabolic inhibitors (Lupetti et al., 2002; Le et al., 2017). Such multifaceted mechanisms of action reduce the development of microbial drug resistance.

After considering the secondary structure (membranedisrupting property of $\alpha$-helix), biological functions (not fully explored antifungal activity), and mechanism of action (decreased probability of resistance due to a multifaceted mechanism of action), we designed and screened $\alpha$-helical peptides that target $C$. albicans with multiple mechanisms. The different physicochemical and structural properties of the antifungal activities of AMPs were investigated. From a hexapeptide named $\mathrm{KV}$, truncated from the $\alpha$-helical region of porcine myeloid antimicrobial peptide-36 (Lv et al., 2014), a series of peptides were designed. To obtain proper amphiphilicity, the reverse tandem duplication method was used to increase the length of the peptides (designated as KV2 and KV3). An arginine (Arg)-substituted analog was then designed by replacing the lysine (Lys) with Arg to increase its cationic ability (designated as RV3). Finally, valine (Val) residues were replaced with aromatic hydrophobic amino acids. Tryptophan (Trp) and phenylalanine (Phe) were replaced separately on the lysine-containing peptide (KV3) and arginine-containing peptide (RV3) to obtain KF3, KW3, RF3, and RW3.

The secondary structures of the designed peptides were determined using circular dichroism (CD) spectroscopy in aqueous and membrane-mimetic media. Evaluation of the antifungal efficacy of these peptides was done by determining their minimum inhibitory concentrations (MICs) against various fungal strains (including FLU-resistant clinical isolates of C. albicans). Hemolytic and cytotoxic activities assessed the toxic effects of these peptides on mammalian cells. The determination of fungicidal rates of these peptides was determined by time-kill kinetics. The fluorescent probe, flow cytometry, and electron microscopy were used to elucidate on their antifungal mechanisms.

\section{MATERIALS AND METHODS}

\section{Peptide Synthesis and Physiochemical Properties Analysis}

Peptides were synthesized by Sangon Biotech (Shanghai, China) using N-9-fluorenylmethyloxycarbonyl (Fmoc) solid-phase synthesis and purified by reverse-phase high-performance liquid chromatography on Inertsil ODS-SP column $(250 \times 4.60 \mathrm{~mm}$, with 5- $\mu \mathrm{m}$ internal particles) (GL Sciences, Tokyo, Japan). The fidelity and precise molecular mass were confirmed 
using electrospray ionization mass spectrometry (LCMS-2020, Shimadzu, Kyoto, Japan). Peptide purity used in the biologic assay was higher than 95\%. The physicochemical properties of the peptides were calculated using the bioinformatics program HeliQuest ${ }^{1}$. The helical wheel projection was performed online using the helical wheel projection ${ }^{2}$. The secondary structure content of the peptide was estimated online by the K2D3 server $^{3}$ (Louis-Jeune et al., 2012).

\section{Secondary Structural Analysis}

Secondary structure analysis of the peptide was performed using a J-820 spectropolarimeter (Jasco, Tokyo, Japan) equipped with a 1-mm-path-length quartz cell at $25^{\circ} \mathrm{C}$. The peptides were dissolved in 10-mM phosphate-buffered saline (PBS) ( $\mathrm{pH} 7.4$ ) or 30-mM sodium dodecyl sulfate (SDS) (Sigma-Aldrich, St. Louis, $\mathrm{MO}$, United States) to give a final concentration of $150 \mu \mathrm{M}$. CD spectra were collected at a wavelength ranging from 190 to $250 \mathrm{~nm}$ with a scan rate of $100 \mathrm{~nm} / \mathrm{min}$, and each spectrum was the average of three scans. The following equation calculated the mean residue ellipticity $\left(\theta_{M}\right.$, deg $\left.\mathrm{cm}^{2} \mathrm{dmol}^{-1}\right)$ :

$$
\theta_{M}=\left(\theta_{o b s} \times 1,000\right) \div(c \times l \times n)
$$

where $\theta_{o b s}$ is the observed ellipticity (mdeg), $c$ is the concentration $(\mathrm{mM})$ of peptide solution, 1 is the path length $(\mathrm{mm})$, and $\mathrm{n}$ is the number of peptide residues.

\section{Fungal Strains}

Candida albicans cgmcc 2.2086, Candida tropicalis cgmcc 2.1975, and Candida parapsilosis cgmcc 2.3989 were purchased from the China General Microbiological Culture Collection Center (Beijing, China). Clinical isolated C. albicans sp3902, C. albicans sp3903, C. albicans sp3931, and C. albicans sp3876 were kindly provided by the School of Basic Medical Sciences, Nanchang University (Jiangxi, China). Clinical isolated C. albicans 56453, C. albicans 56214, C. albicans 14926, C. albicans 17546, and C. albicans 58288 were kindly provided by Zhongshan Hospital Affiliated to Fudan University (Shanghai, China).

\section{Antifungal Activity Assay}

The antifungal activity of the peptide was determined using the broth microdilution method previously described (Yang et al., 2019). FLU (Sigma-Aldrich, Shanghai, China) and amphotericin B (AmB) (Sigma-Aldrich, St. Louis, MO, United States) were used as controls to compare the antifungal efficacies of the designed peptides.

Briefly, colonies from 24-h culture grown in yeast extract peptone dextrose (YPD) (AOBOXA, Beijing, China) agar medium were suspended in sterile saline to obtain stock inoculum suspensions with concentrations of optical density at $625 \mathrm{~nm}$ (OD625) of $0.08-0.1$. The working suspensions were made by 1:1,000 dilutions of the stock suspensions with Roswell Park Memorial Institute (RPMI) 1640 (Gibco, Thermo Fisher

\footnotetext{
${ }^{1}$ http://heliquest.ipmc.cnrs.fr/cgi-bin/ComputParamsV2.py

${ }^{2}$ http://rzlab.ucr.Edu/scripts/wheel/wheel.cgi

${ }^{3}$ http://cbdm-01.zdv.uni-mainz.de/ andrade/k2d3/
}

Science, Inc.) buffered with morpholinepropanesulfonic acid (MOPS) (Sigma-Aldrich, St. Louis, MO, United States) at pH 7.0. The final concentrations of the working inoculum suspensions of the isolates were $1-2 \times 10^{3}$ colony-forming units $(\mathrm{CFU}) / \mathrm{ml}$, as determined by quantitative colony counts on YPD agar medium. Peptides and antifungal agents were twofold serially diluted in 0.2 bovine serum albumin (Sigma-Aldrich, Shanghai, China) and RPMI-MOPS medium and then mixed with equal volumes of prepared fungal suspension in 96-well plates. After that, each well had a 100- $\mu$ l mixture, and the final concentration ranges of FLU, $\mathrm{AmB}$, and peptides were 256 to $0.5,64$ to 0.03 , and 64 to $1 \mu \mathrm{M}$, respectively. The microdilution plates were incubated at $28^{\circ} \mathrm{C}$ for $48 \mathrm{~h}$. The MICs were determined by the absorbance at $492 \mathrm{~nm}$ with a microplate reader as the lowest peptide concentration that inhibited $99 \%$ of the fungal growth. Fifty-microliter samples of each well were further removed and plated on YPD agar plates. The plates were incubated at $28^{\circ} \mathrm{C}$ for $48 \mathrm{~h}$. The minimum fungicidal concentrations (MFCs) were determined as the lowest peptide concentration that completely killed fungal cells.

\section{Time-Kill Kinetics Assay}

The killing kinetics of the peptides against $C$. albicans was recorded in terms of $\mathrm{CFU}$ per milliliter at different times of incubation. C. albicans cgmcc 2.2086 and C. albicans 56241 were diluted to approximately $10^{5} \mathrm{CFU} / \mathrm{ml}$ and incubated with peptides at concentrations of $1 \times$ MIC and $2 \times$ MIC. The mixtures were incubated at $37^{\circ} \mathrm{C}$. At the predetermined time interval $(10,30,60$, and $120 \mathrm{~min})$, the fungal suspensions were diluted with PBS and plated on YPD agar plates, and colonies were counted after $48 \mathrm{~h}$ of incubation. Results were obtained from three independent experiments.

\section{Hemolysis Assays}

Hemolytic activities of the peptide were determined according to the method previously described (Lyu et al., 2019). The experimental protocol was reviewed and approved by the ethics committee of the Northeast Agriculture University Hospital, and the experimental method was carried out in accordance with the approved guidelines and regulations [NEAU-(2011)9]. Fresh heparinized human whole blood from a healthy donor was centrifuged at $1,000 \mathrm{~g}$ for $5 \mathrm{~min}$ at $4^{\circ} \mathrm{C}$. The obtained erythrocytes were washed three times and resuspended in PBS. Subsequently, serial dilutions of the peptides were mixed with erythrocytes and incubated for an hour at $37^{\circ} \mathrm{C}$. Erythrocytes treated with PBS or $0.1 \%$ Triton X-100 (SigmaAldrich, Shanghai, China) were used as a negative or positive control, respectively. After centrifugation, the supernatant was transferred into a new 96-well plate, and released hemoglobin was measured using a multimode microplate reader (Infinite M200 Pro, Tecan, Switzerland) at $570 \mathrm{~nm}$. The percent lysis was calculated according to the following equation:

$$
\text { hemolysis }(\%)=\left[\left(A-A_{0}\right) \div\left(A_{t}-A_{0}\right)\right]
$$

where $A$ is the absorbance of the peptide sample, $A_{0}$ and $A_{t}$ represent 0 and $100 \%$ hemolysis determined in $10-\mathrm{mM}$ PBS and 
$0.1 \%$ Triton X-100, respectively. Results were derived from three independent experiments, each performed in triplicate.

\section{Cytotoxicity Assays}

The cytotoxic effects of the peptides on porcine intestinal epithelial cell line (IPEC-J2) and porcine mammary epithelial cells (PMEC) were determined using 3-(4,5-dimethylthiazol-2yl)-2,5-diphenyltetrazolium bromide (MTT) assays. Viable cells contain $\mathrm{NAD}(\mathrm{P}) \mathrm{H}$-dependent oxidoreductase enzymes, which reduce the MTT reagent to formazan, an insoluble crystalline product with a deep purple color. The darker the solution, the greater the number of viable, metabolically active cells. This method was performed as previously described (Chou et al., 2019). Briefly, cells were seeded in 96-well cell culture plates with approximately 5,000 cells per well. After overnight culture at $37^{\circ} \mathrm{C}$ in $5 \%$ carbon dioxide, the cells were treated with various concentrations of peptide for $24 \mathrm{~h}$. Subsequently, cells were incubated with $50 \mu \mathrm{l}$ of MTT $(0.5 \mathrm{mg} / \mathrm{ml})$ (Sigma-Aldrich, Shanghai, China) for $4 \mathrm{~h}$. After incubation, 96-well plates were centrifuged at $1,000 \mathrm{~g}$ for $5 \mathrm{~min}$, and the supernatants were discarded, and $150 \mu \mathrm{l}$ of dimethyl sulfoxide (Solarbio, Beijing, China) was added to dissolve the formazan crystals. Finally, the absorbance at $570 \mathrm{~nm}$ was measured with a multimode microplate reader (Infinite M200 Pro, Tecan, Switzerland). Results were derived from three independent experiments, each performed in triplicate.

\section{Calculation of the Therapeutic Index}

The therapeutic index (TI) is a quantitative measurement of the relative safety of the peptide. It is calculated by the ratio of $\mathrm{HC} 10$ (hemolytic activity) to GM (antimicrobial activity). HC10 is the minimal hemolytic concentration that induced a $10 \%$ hemolysis of human erythrocytes. GM is the geometric mean of the MIC values of a peptide against all the tested C. albicans. The larger the TI, the better the cell selectivity the peptide has.

\section{Drug Resistance Experiment}

Drug resistance was induced by treating C. albicans repeatedly with antifungal agents, as previously described (Chou et al., 2019). Briefly, MIC testing was first conducted for tested peptides and antifungal agents, as described earlier. At the end of incubation $\left(28^{\circ} \mathrm{C}\right.$ for $\left.48 \mathrm{~h}\right)$, the fungal cells growing in the well with the half-MIC concentration were harvested and adjusted to an OD625 of 0.08 to 0.1 . After a 1:1,000 dilution with the RPMIMOPS medium, the inoculum was subjected to the next passage MIC testing, and the process was repeated for 11 passages.

\section{Membrane Potential Assays}

The alteration of membrane potential in peptide-treated C. albicans was detected using the membrane potential-sensitive fluorescent probe, 3,3'-dipropylthiadicarbocyanine iodide [DiSC3(5)] (Sigma-Aldrich, Shanghai, China), as previously described (Qi et al., 2010). In brief, C. albicans cells in midlogarithmic growth-phase were harvested and suspended to an OD600 of 0.05 with 5-mM 4-(2-hydroxyethyl)-1piperazineethanesulfonic acid buffer ( $\mathrm{pH}$ 7.4, containing $20-\mathrm{mM}$ glucose). After the addition of $0.4-\mu \mathrm{M} \operatorname{DiSC} 3(5)$, samples were incubated for $90 \mathrm{~min}$ in the dark to obtain a stable reduction in fluorescence, and then, potassium chloride (4 M) was added to the cell suspension to give a final concentration of $100 \mathrm{mM}$. Subsequently, $2 \mathrm{ml}$ of cell suspension was added to a $1-\mathrm{cm}$ quartz cuvette and mixed with peptides at different concentrations. The changes in fluorescence were recorded for $900 \mathrm{~s}$ with an F-4500 fluorescence spectrophotometer (Hitachi, Japan) at excitation and emission wavelengths of 622 and $670 \mathrm{~nm}$, respectively.

\section{Flow Cytometry Analysis}

Analysis of the membrane integrity of C. albicans cgmcc 2.2086 after peptide treatment was performed by flow cytometry. As previously described ( $\mathrm{Li}$ et al., 2016), C. albicans cells were harvested at the logarithmic phase and adjusted to a cell density of $1 \times 10^{6} \mathrm{CFU} / \mathrm{ml}$ in RPMI-MOPS medium. Cell suspensions were incubated for $90 \mathrm{~min}$ with peptides at desired concentrations. Subsequently, treated cells were incubated with $10-\mu \mathrm{g} / \mathrm{ml}$ propidium iodide (PI) (Solarbio, Beijing, China) for $15 \mathrm{~min}$, followed by washing and resuspension in PBS. PI fluorescence was collected by a FACScan instrument (BectonDickinson, San Jose, CA).

\section{Membrane Morphological Observation}

Morphological alteration in C. albicans cells after peptide treatment was visualized by electron microscopy. For the scanning electron microscope (SEM) sample preparation, logarithmic C. albicans cgmcc 2.2086 were harvested and resuspended to an OD600 of 0.2 and incubated for $90 \mathrm{~min}$ with peptide at the desired concentration. After incubation, cells were collected through centrifugation and fixed overnight with $2.5 \%(\mathrm{v} / \mathrm{v})$ glutaraldehyde at $4^{\circ} \mathrm{C}$. After that, samples were dehydrated with an ascending ethanol series $(50,70$, 90 , and $100 \%$ ). Dried samples were transferred to a mixture $(1: 1, \mathrm{v} / \mathrm{v})$ of ethanol and tertiary butanol for $20 \mathrm{~min}$, followed by pure tertiary butanol for $1 \mathrm{~h}$. Specimens were dried and coated with gold and visualized using a HITACHI S-4800 SEM (Hitachi, Japan).

For transmission electron microscope (TEM) analysis, microbial samples were initially prepared as described earlier for SEM analysis. After prefixation with $2.5 \%$ glutaraldehyde overnight, cell pellets were washed three times with PBS and postfixed with $2 \%$ osmium tetroxide in PBS for 70 min. Samples were washed twice with PBS, followed by dehydration with a graded ethanol series (50,70,90, and 100\%) and immersed in pure epoxy resin in a constant-temperature incubator overnight. Finally, specimens were sectioned using an ultramicrotome, stained with uranyl acetate and lead citrate, and observed using a HITACHI H-7650 TEM (Hitachi, Japan).

\section{Intracellular Reactive Oxygen Species Production}

The level of intracellular reactive oxygen species (ROS) was measured by the fluorometric assay, as previously described (Wang et al., 2018). C. albicans cgmcc 2.2086 cells were harvested at the logarithmic phase and adjusted to a final concentration 
of OD600 of 0.6 and incubated with different concentrations of peptides for $60 \mathrm{~min}$ at $37^{\circ} \mathrm{C}$. After treatment, fungal cells were stained with $10-\mu \mathrm{M} 2^{\prime}, 7^{\prime}$-dichlorofluorescein diacetate (DCFH-DA) for $60 \mathrm{~min}$. At the end of incubation, cells were washed twice with PBS to remove the excessive DCFH-DA. The fluorescence intensities were recorded (excitation $488 \mathrm{~nm}$ and emission $525 \mathrm{~nm}$ ) with a multimode microplate reader (Infinite M200 Pro, Tecan, Switzerland). Results were derived from three independent experiments, each performed in triplicate.

\section{Statistical Analysis}

All data were expressed as mean \pm standard deviation (SD). Differences were analyzed using one-way ANOVA or a Student's $t$-test. Statistical analyses were performed with SPSS software 20.0 (Chicago, IL, United States). A p-value of 0.05 or less was considered statistically significant. HC10 and IC50 values were calculated by using probit regression in SPSS 20.0.

\section{RESULTS}

\section{Peptide Characteristics}

The sequences and key physicochemical properties of the peptides are summarized in Table 1. Accurate molecular masses of the synthesized peptides were consistent with their theoretical molecular masses, indicating the successful synthesis of all designed peptides. As shown in Table 1, peptides with 18 amino acid residues presented seven net charges. Hydrophobicity $(\mathrm{H})$ values were calculated by the summation of hydrophobicity of all amino acids divided by the sequence length of the peptide. These values decreased in the order of KW3, RW3, KF3, RF3, KV3, and RV3, corresponding to reducing values.

\section{Secondary Structures}

Secondary structure transitions that were triggered by environmental alterations were investigated using CD spectroscopy. Mimicry of the microbial cell membrane environment was done using an anionic surfactant SDS. The designed peptides displayed unordered structures in an aqueous solution (10-mM PBS) and adopted $\alpha$-helical structures (double minima at 208 and $222 \mathrm{~nm}$ ) in the membrane mimicry environment (30-mM SDS). However, the KV still appeared as an unordered structure in $30-\mathrm{mM}$ SDS (Figure 1). Accurate $\alpha$-helical contents of the tested peptides were calculated from $\mathrm{CD}$ spectral data using online server $\mathrm{K} 2 \mathrm{D} 3$, and the results are presented in Table 2. Compared with KV2, KV3 (which consisted of 18 amino-acid residues) showed a $42.52 \%$ increase in $\alpha$-helical content in the secondary structure (Table 2). Valine-containing peptides KV3 and RV3, with 52.15 and 57.35\% $\alpha$-helix, respectively, exhibited a strong $\alpha$-helical propensity, whereas peptides containing Phe (KF3 and RF3) exhibited low $\alpha$-helix contents (39.89 and $43.33 \%$, respectively). The incorporation of tryptophan changed the $\alpha$-helix content to a lesser extent. KW 3 and RW3 showed a $2.78 \%$ decrease and a $4.2 \%$ increase in helical contents compared with their valine-containing counterparts, KV3 and RV3, respectively.

\section{Antifungal Activities}

The antifungal activities of the designed peptides are summarized in Table 3. The GMs of the MIC values of the peptides against C. albicans strains were calculated and presented in Table 4. KV and KV2 were inactive against all Candida strains, whereas KV3 exhibited a slight antifungal activity with MIC values ranging from 16 to $64 \mu \mathrm{M}$ on Candida strains (Table 3). Substituting Lys residues in KV3 with Arg (designated as RV3) resulted in a twofold increase in anticandidal activities on C. albicans. Aromatic amino acid substitutions improved the antifungal activities of the peptides. KW3, RF3, and RW3, whose GM values were 5.28, 6.96, and $3.48 \mu \mathrm{M}$, respectively, exhibited the strongest antifungal activities against C. albicans (Table 4). Clinically isolated $C$. albicans strains that were resistant to FLU were highly susceptible to the three peptides. Melittin, an $\alpha$-helix peptide, was used as a positive control to evaluate the antifungal effects of the $\alpha$-helical peptides. Table 3 shows that melittin displayed strong inhibition effects on the growth of C. albicans. The prevalence of non-C. albicans strains have been increasing over time (Berkow and Lockhart, 2017). Therefore, the antifungal activities of these peptides against non-C. albicans strains were also evaluated. Table 3 shows that these peptides were also shown to be active against C. tropicalis and C. parapsilosis. The MFCs of the peptides were also determined, and the results were presented in Supplementary Table 1. The MFC values of peptides were approximately two times comparable with their MICs. Compared with the fungistatic agent FLU, the designed peptides were fungicidal.

\section{Hemolytic Activity and Cytotoxicity}

The hemolytic activity of peptides was analyzed in human erythrocytes. Peptide concentrations that induced $10 \%$ hemolysis were calculated and presented in Table 4. Figure 2 shows that most of the peptides exhibited slight hemolytic activities at the highest tested concentration $(64 \mu \mathrm{M})$. However, KW3 and RW3 exhibited strong hemolytic activities. KW3 and RW3 at a concentration of 2.69 and $3.81 \mu \mathrm{M}$, respectively, induced a $10 \%$ hemoglobin release (Table 4). With an HC10 value of $0.91 \mu \mathrm{M}$, melittin exhibited the highest hemolytic activity.

The cytotoxicity profiles of the peptides on IPEC-J2 and PMEC cells were determined using the MTT assay. Figure 3 shows that KV3 and RV3 had negligible cytotoxic effects on IPEC-J2 and PMEC cells. However, the antifungal activities of these peptides were not observed. At the respective concentrations of 4 and $8 \mu \mathrm{M}, \mathrm{KW} 3$ and RW3 started to exhibit statistically significant cytotoxic effects. KW3 (IC50 $=6.84 \mu \mathrm{M}$ on IPEC-J2 cells and 10.26 $\mu \mathrm{M}$ on PMEC cells) and RW3 (IC50 $=14.78 \mu \mathrm{M}$ on IPEC-J2 cells and 22.29 $\mu \mathrm{M}$ on PMEC cells) were the most toxic peptides (Figure 3 and Supplementary Table 2). KF3 and RF3 maintained high cell survival rates at $32 \mu \mathrm{M}$, but a sharp rise in cytotoxicity on both cell lines was observed at $64 \mu \mathrm{M}$.

\section{Cell Selectivity and Time-Kill Kinetics}

The TI is a parameter representing the cell selectivity of a peptide. It is calculated by the ratio of $\mathrm{HC} 10$ (hemolytic activity) to GM 
TABLE 1 | Amino acid sequences and key physicochemical parameters of the peptides.

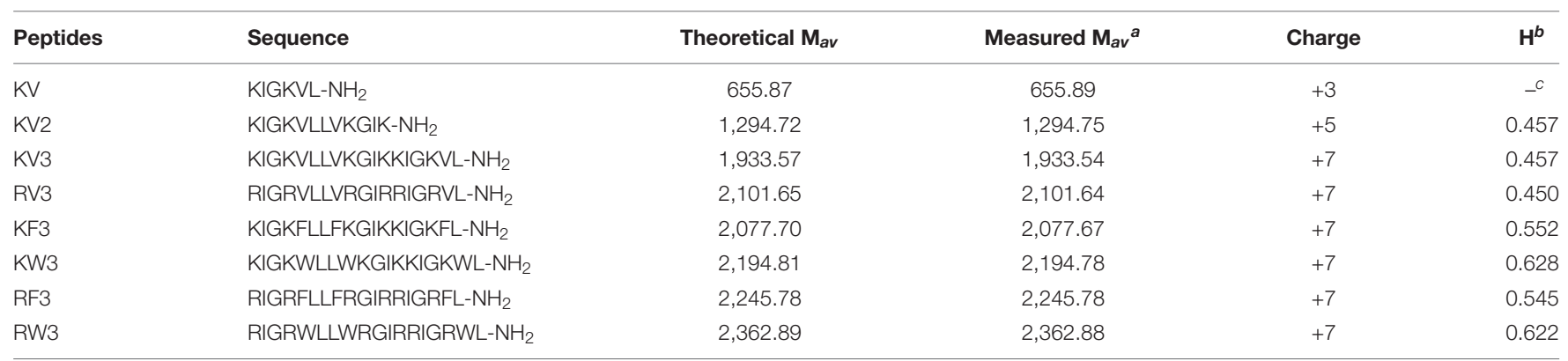

${ }^{a}$ Molecular average mass (Mav) was measured by electrospray ionization mass spectrometry (ESI MS). ${ }^{b}$ Hydrophobicity (H) was calculated using the online program HeliQuest (http://heliquest.ipmc.cnrs.fr/cgi-bin/ComputParamsV2.py). ' Hydrophobicity (H) of KV was not available due to the shorter chain length than minimum chain length required for calculation.

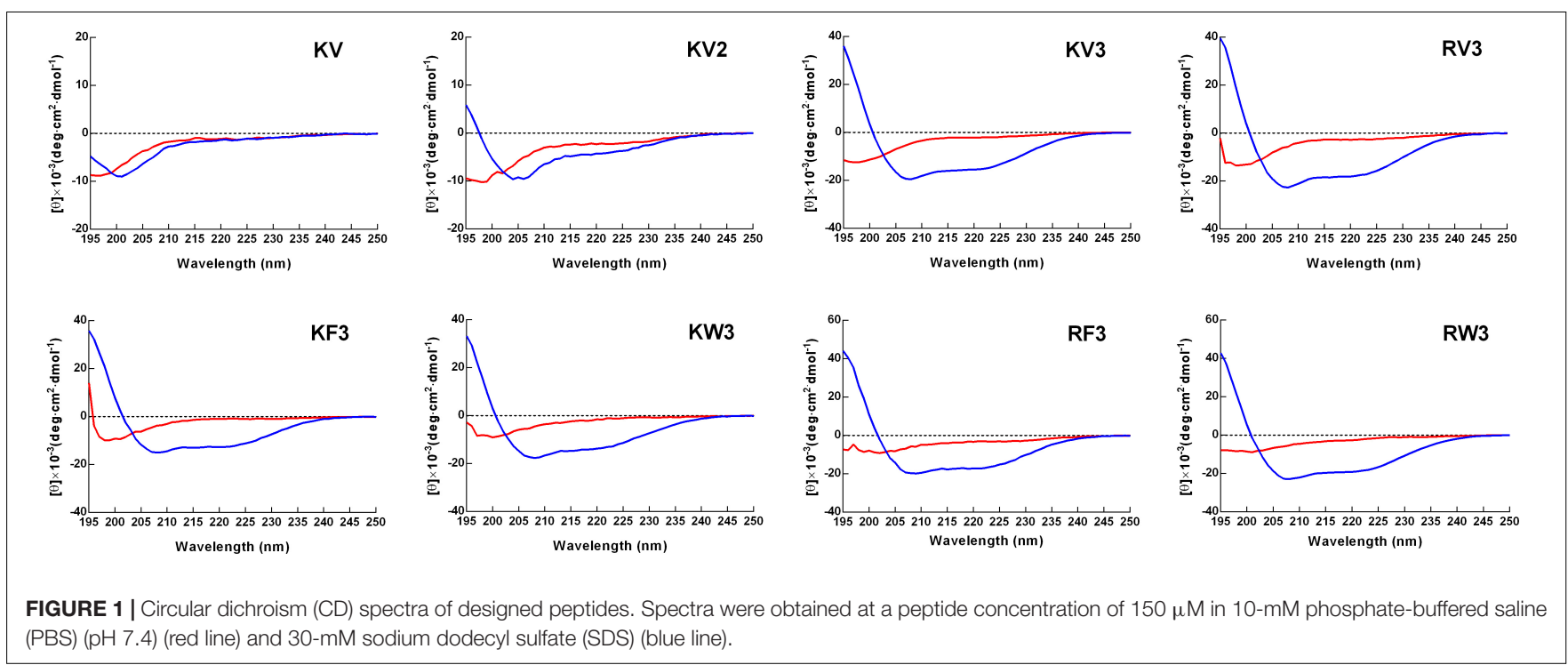

TABLE 2 | Percentage of $\alpha$-helical structure in designed peptides in different solutions.

\begin{tabular}{lccccc}
\hline \multirow{2}{*}{ Peptides } & \multicolumn{2}{c}{ PBS $^{\mathbf{a}}$} & & \multicolumn{2}{c}{ SDS $^{\mathbf{b}}$} \\
\cline { 2 - 3 } \cline { 5 - 6 } & $\boldsymbol{( \theta )} \mathbf{2 2 2}^{\mathbf{c}}$ & $\boldsymbol{\alpha}$-helix (\%) & & $(\boldsymbol{\theta}) \mathbf{2 2 2} \mathbf{c}^{\mathbf{c}}$ & $\boldsymbol{\alpha}$-helix (\%) \\
\hline KV & $-1,168.30$ & 3.25 & & $-1,449.66$ & 5.10 \\
KV2 & $-2,281.50$ & 2.97 & & $-4,138.67$ & 9.63 \\
KV3 & $-2,055.96$ & 3.22 & & $-15,067.66$ & 52.15 \\
RV3 & $-2,499.47$ & 3.18 & & $-17,452.07$ & 57.35 \\
KF3 & -753.64 & 5.34 & & $-12,478.98$ & 39.89 \\
KW3 & $-1,050.36$ & 3.30 & & $-13,046.52$ & 49.34 \\
RF3 & $-3,068.10$ & 2.68 & & $-17,014.84$ & 43.33 \\
RW3 & $-2,088.51$ & 4.83 & & $-18,453.47$ & 61.55 \\
\hline
\end{tabular}

apeptides were dissolved in 10-mM phosphate-buffered saline (PBS) ( $p H$ 7.4). ${ }^{b}$ Peptides were dissolved in 30-mM sodium dodecyl sulfate (SDS). ${ }^{c}$ Mean residue ellipticities ( $\theta$ ) (deg $\mathrm{cm}^{2} \mathrm{dmol}^{-1}$ ) at wavelength $222 \mathrm{~nm} .{ }^{d} \alpha$-Helical structure content was calculated online using K2D3 (http://cbdm-01.zdv.uni-mainz.de/ andrade/k2d3/).

(antimicrobial activity). As shown in Table 4, RF3 displayed strong cell selectivity properties toward C. albicans over human erythrocytes. Its TI value (18.39) was 20 times higher than that of melittin. In contrast, the other two effective peptides, KW3 and RW3, exhibited poor cell selectivities due to their high hemolytic activities.

Time-kill kinetics of RF3 was performed on C. albicans cgmcc 2.2086 and C. albicans 56214 at concentrations of $1 \times$ MIC and $2 \times$ MIC, respectively. As shown in Figure 4, RF3 displayed concentration-dependent killing. After 2-h treatment, the lower concentration $(1 \times$ MIC) of RF3 did not eliminate the colonies but produced 2.2$\log \mathrm{CFU}$ and 2.1-log CFU reductions in C. albicans cgmcc 2.2086 and C. albicans 56214 strains, respectively. At $2 \times$ MIC concentration, no fungal growth was observed after incubation.

\section{Development of Resistance}

To investigate the potential of fungi to develop drug resistance against RF3, C. albicans cgmcc 2.2086 were exposed toward sub-MIC concentrations of RF3 over 10 passages. Conventional antifungal agent FLU was used as control. As shown in Figure 5, exposure to a subinhibitory concentration of FLU induced an eightfold MIC-increase of FLU in C. albicans following 10 passages, whereas the 
TABLE 3 | Antifungal activity of the peptides.

\begin{tabular}{|c|c|c|c|c|c|c|c|c|c|c|c|}
\hline & \multicolumn{11}{|c|}{$\operatorname{MIC}(\mu M)^{a}$} \\
\hline & KV & KV2 & KV3 & RV3 & KF3 & KW3 & RF3 & RW3 & Melittin & FLU $^{\mathbf{b}}$ & $\mathrm{AmB}^{\mathrm{c}}$ \\
\hline C. albicans cgmcc 2.2086 & $>64$ & $>64$ & 32 & 32 & 32 & 4 & 8 & 4 & 4 & 2 & 1 \\
\hline C. albicans 56452 & $>64$ & $>64$ & 32 & 16 & 16 & 4 & 8 & 4 & 8 & $>256$ & 1 \\
\hline C. albicans 56214 & $>64$ & $>64$ & 32 & 16 & 16 & 4 & 4 & 2 & 4 & $>256$ & 1 \\
\hline C. albicans 14936 & $>64$ & $>64$ & $>64$ & 32 & 64 & 8 & 8 & 4 & 4 & 32 & 0.25 \\
\hline C. albicans 17546 & $>64$ & $>64$ & 64 & 64 & 64 & 8 & 8 & 8 & 8 & $>256$ & 0.25 \\
\hline C. albicans 58288 & $>64$ & $>64$ & 64 & 32 & 32 & 8 & 8 & 4 & 4 & 8 & 0.5 \\
\hline C. albicans sp3902 & $>64$ & $>64$ & 64 & 32 & 16 & 2 & 8 & 2 & 2 & 16 & 0.25 \\
\hline C. albicans sp3903 & $>64$ & $>64$ & 64 & 32 & 32 & 4 & 8 & 2 & 4 & 16 & 0.13 \\
\hline C. albicans sp3931 & $>64$ & $>64$ & 64 & 32 & 32 & 8 & 8 & 4 & 8 & 1 & 0.25 \\
\hline C. albicans sp3876 & $>64$ & $>64$ & 16 & 32 & 64 & 8 & 4 & 4 & 4 & $>256$ & 0.25 \\
\hline C. tropicalis cgmcc 2.1975 & $>64$ & $>64$ & 16 & 8 & 8 & 2 & 8 & 2 & 4 & 4 & 1 \\
\hline C. parapsilosis cgmcc 2.3989 & $>64$ & $>64$ & 32 & 16 & 32 & 8 & 16 & 4 & 2 & 4 & 2 \\
\hline
\end{tabular}

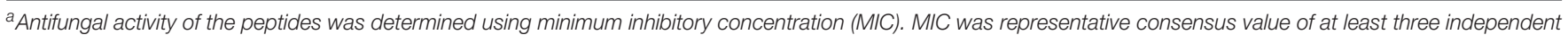

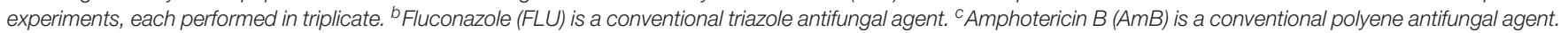

TABLE 4 | Specificity of the peptides.

\begin{tabular}{lccc}
\hline Peptides & $\mathbf{G M}(\boldsymbol{\mu} \mathbf{M})^{\mathbf{a}}$ & $\mathbf{H C 1 0}(\boldsymbol{\mu} \mathbf{M})^{\mathbf{b}}$ & TI $^{\mathbf{c}}$ \\
\hline KV3 & 48.5 & $>64$ & 2.64 \\
RV3 & 29.86 & $>64$ & 4.29 \\
KF3 & 32 & $>64$ & 4.00 \\
KW3 & 5.28 & 2.69 & 0.51 \\
RF3 & 6.96 & $>64$ & 18.39 \\
RW3 & 3.48 & 3.81 & 1.09 \\
Melittin & 4.59 & 0.91 & 0.20 \\
\hline
\end{tabular}

${ }^{a} G M$, the geometric mean of the minimum inhibitory concentration (MIC) values of the peptides against tested Candida albicans strains. When no detectable antifungal activity against C. albicans was observed at $64 \mu \mathrm{M}$, a value of $128 \mu \mathrm{M}$ was used for the calculation of GM. ${ }^{b} \mathrm{HC10}$, the hemolytic concentration of the peptides that induced $10 \%$ hemolysis of human blood red cells. ${ }^{C}$ Therapeutic index (TI) is calculated as HC10/GM. Higher TI values represent greater specificity of the peptides.

MIC of RF3 remained constant during 10 passages. This result suggested that fungal resistance to RF3 was not generated easily.

\section{Cytoplasmic Membrane Depolarization}

The ability of RF3 to depolarize the cytoplasmic membrane of $C$. albicans was evaluated by the potentiometric probe DiSC3(5). DiSC3(5) accumulates on hyperpolarized membranes and translocates into the lipid bilayer, leading to fluorescence selfquenching. Upon depolarization, the dye is rapidly released into the medium resulting in increased fluorescence (Te Winkel et al., 2016). The RF3 and melittin that induced cytoplasmic membrane depolarization of C. albicans cgmcc 2.2086 were monitored for a period of 900 s. As shown in Figure 6, RF3 depolarized fungal cytoplasmic membranes in a concentration-dependent manner. However, at a concentration of $0.5 \times$ MIC, melittin elicited stronger membrane depolarization. RF3 was more effective in depolarizing the cytoplasmic membrane of $C$. albicans cgmcc 2.2086 at $1 \times$ MIC and $2 \times$ MIC concentrations.

\section{Membrane Permeabilization}

The effect of RF3 on membrane permeability was determined by flow cytometry using PI, a membrane-impermeable fluorescent dye. Nucleic acids stained with PI suggested a loss of membrane integrity (Lam et al., 2016). As shown in Figure 7, RF3 played a strong role in destroying the permeability of $C$. albicans cgmcc 2.2086 cell membrane. This activity was dependent on the concentration of the peptide. In the absence of RF3, the percentage of PI-positive cells was 0.4. After treatment with RF3 at concentrations of $1 \times \mathrm{MIC}$ and $2 \times \mathrm{MIC}$, the cells were found to be more damaged, with 73 and $97.7 \%$ PI fluorescence signals, respectively.

\section{Morphological Observation}

The effect of RF3 treatment on C. albicans cell morphology was visualized using SEM and TEM. Figure 8 shows that untreated cells had intact and smooth membranes. However, the membrane surfaces of RF3-treated cells (Figures 8B,C) appeared rough, shrunken, and irregular. Numerous bleb-like structures were also observed on their surfaces. Membrane integrity and ultrastructural alterations were investigated using TEM. Compared with the untreated cells (Figure 8D), treatment with RF3 caused significant cell membrane breaks and fractures. Also, RF3 treatment-induced large cytoplasmic vacuoles, as shown in Figures 8E,F.

\section{Intracellular Reactive Oxygen Species Production}

The level of intracellular ROS was measured using DCFHDA, which is oxidized by ROS to generate fluorescent $2^{\prime}, 7^{\prime}$ dichlorodihydrofluorescein (Wang et al., 2015). As shown in Figure 9, the ROS generation increased markedly in the presence of RF3. Treatment with RF3 resulted in a concentrationdependent increase in intracellular ROS level. Compared with the control group, treatment with $1 \times$ MIC RF3 induced a 4.1-fold increase in fluorescence intensity. 


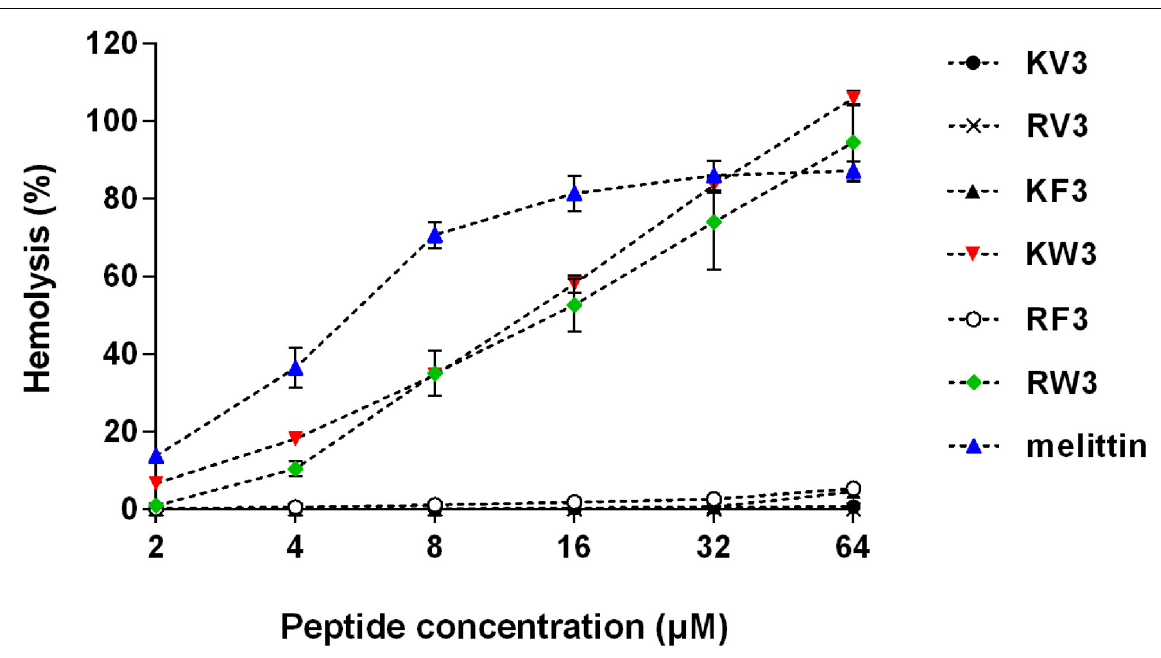

FIGURE 2 | Hemolytic activity of the designed peptides. Human erythrocytes were incubated with peptides $(2-64 \mu \mathrm{M})$ at $37^{\circ} \mathrm{C}$ for $1 \mathrm{~h}$ followed by the measurement of released hemoglobin at $570 \mathrm{~nm}$. Values are means $\pm \mathrm{SD}, n=3$.

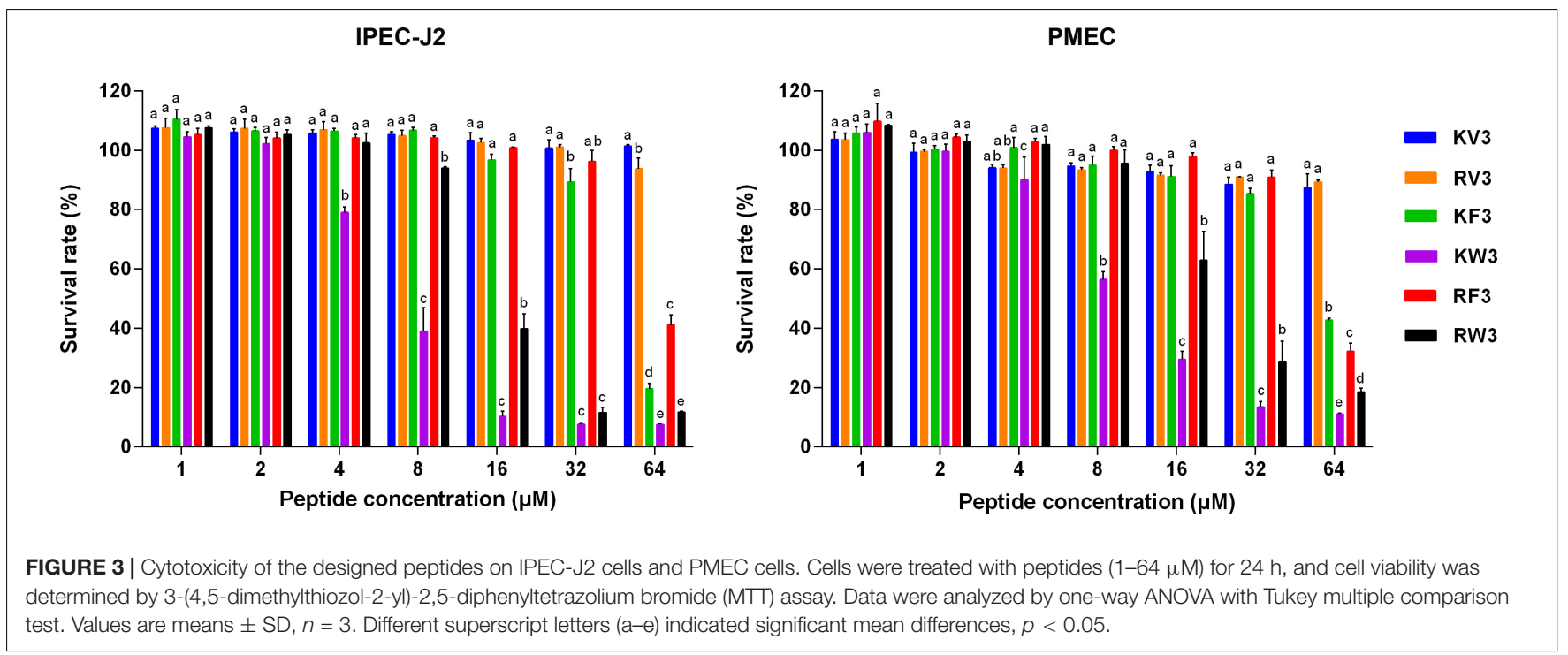

\section{DISCUSSION}

The defective immune system is one of the leading causes of the rise of fungal infection incidences in the past decade. Fungal infections due to Candida species are the most common in this group. C. albicans have developed resistance to clinically available antifungal agents (Wu et al., 2017). The membrane disruption antifungal mechanism of AMPs offers a great avenue for overcoming the drug resistance problem (Wang et al., 2019).

Studies have shown that an increase in peptide length results in increased antimicrobial activity within a certain range (Chou et al., 2016; Wu et al., 2017). Hence, we adopted a signal and double addition of KV to obtain KV2 and KV3. Amphiphilicity is an essential, but, controversial parameter that affects the antimicrobial activity of AMPs. It is a factor that is believed to be crucial in the antimicrobial activity of AMPs. Studies have shown that imperfect amphiphilic peptides had better antimicrobial activities compared with the corresponding perfect amphiphilic peptides (Wiradharma et al., 2013; Wang et al., 2018). Due to reverse tandem duplication, KV3 had an imperfect but relatively better amphiphilicity (Supplementary Figure 1). Additionally, the amino acid composition that determines the cationic and hydrophobic properties and conformation are associated with the antimicrobial and cell-selective properties of the AMPs (Lum et al., 2015; Wu et al., 2015). It has been suggested that Argcontaining peptides have better bactericidal efficacies than Lyscontaining peptides. Aromatic amino acids with bulky side chains serve as anchors in the interactions between AMPs and microbial membranes (Marsh et al., 2007; Zhu et al., 2015). The argininesubstituted analog (designated as RV3) of KV3 was first designed by replacing the Lys residues with Arg. Valine residues in KV3 and RV3 were then replaced by aromatic hydrophobic amino 


\section{C. albicans cgmcc 2.2086}

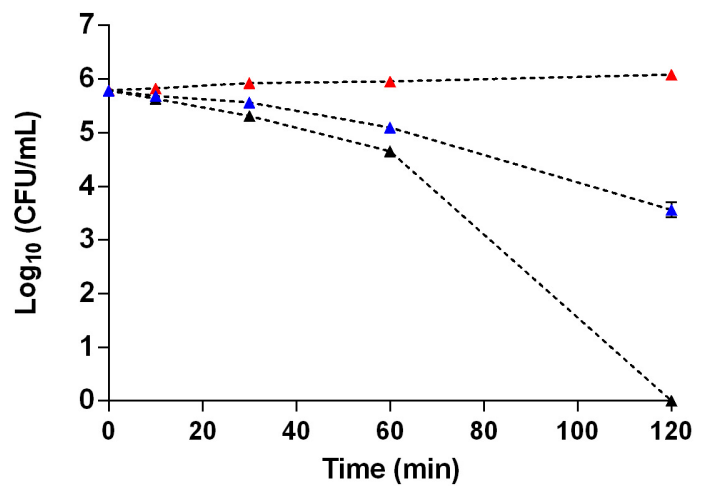

C. albicans 56214

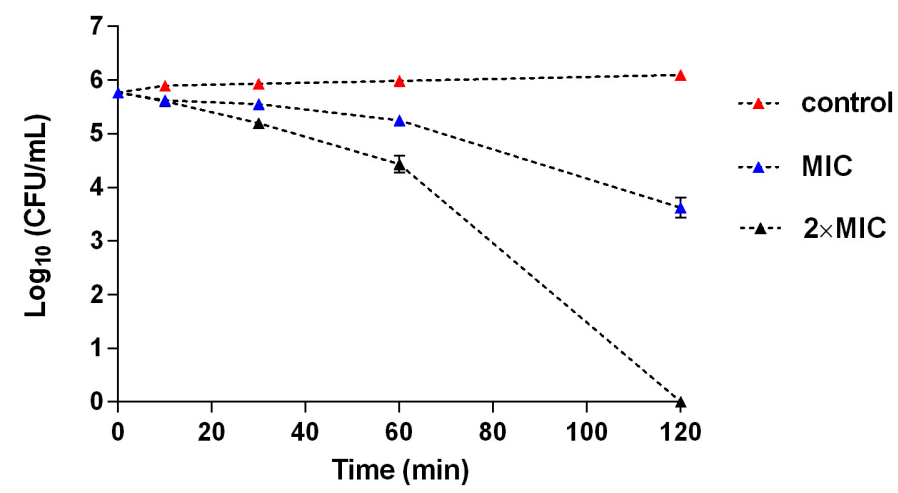

FIGURE 4 | Time-killing kinetics of RF3 against C. albicans cgmcc 2.2086 and C. albicans 56241 . Fungal suspensions were incubated with peptides at concentrations of $1 \times \mathrm{MIC}$ and $2 \times$ MIC. At various time intervals, samples were diluted and plated for colony counts. Values are means $\pm \mathrm{SD}, n=3$.

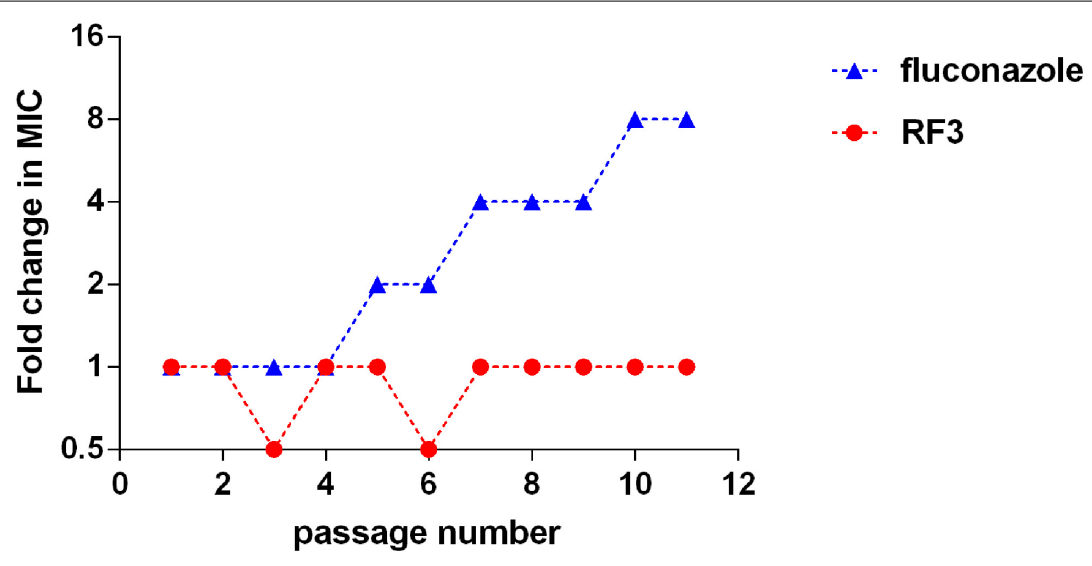

FIGURE 5 | Serial passage of C. albicans cgmcc 2.2086 in the presence of sub-MIC concentration of RF3 or fluconazole.

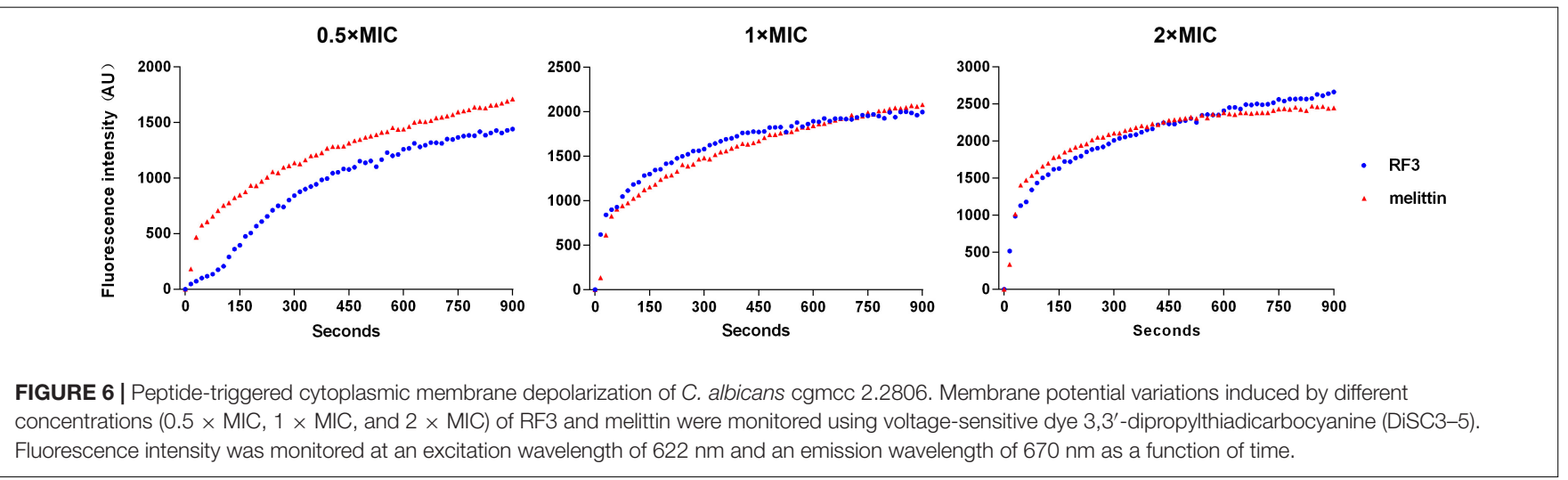

acids, Trp and Phe, respectively, and KF3, KW3, RF3, and RW3 were obtained.

Peptides display unordered conformations in aqueous environments and convert to well-defined structures upon associating with microbial membranes. These conformational transitions influence the insertion of AMPs into the cell membrane (Ciociola et al., 2016; Guilhelmelli et al., 2016). Except for KV, which was too short of forming stable secondary structures, the designed peptides folded into $\alpha$-helical structures in 30-mM SDS (Figure 1). Compared with KV, increased helical propensities were observed in KV2 and KV3 (Figure 1 and Table 2). The hydrogen-bonding interactions along the helical 

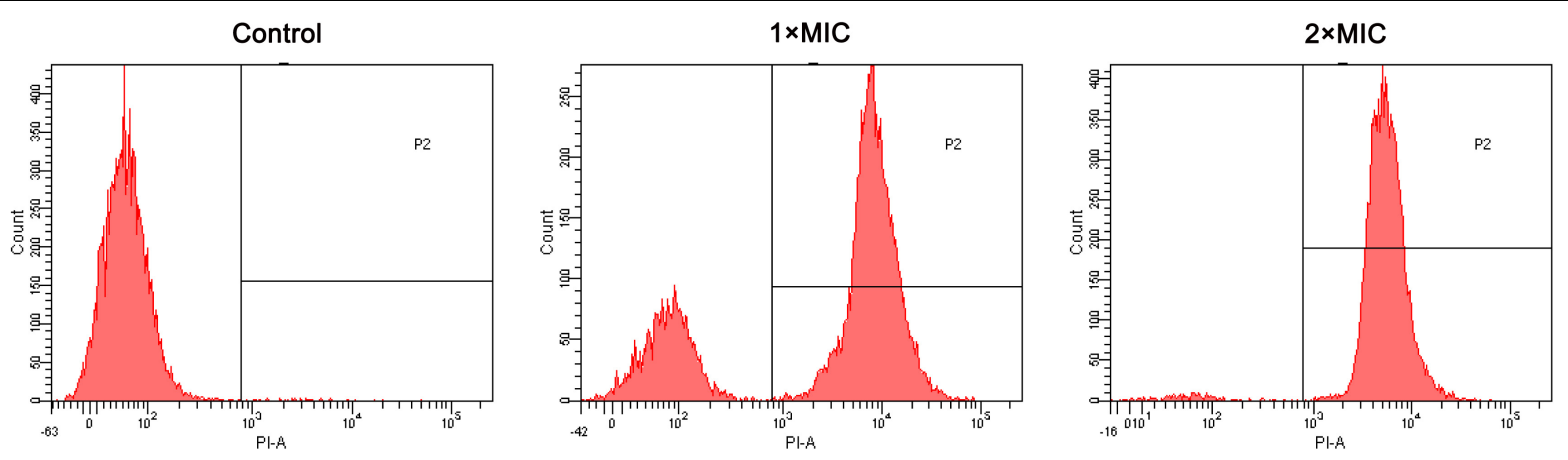

FIGURE 7 | RF3 induced membrane permeabilization of $C$. albicans cgmcc 2.2086 . Fluorescence intensity of propidium iodide (PI) (10 $\mu \mathrm{g}$ ml ${ }^{-1}$ ) after $90-\mathrm{min}$ treatment with different concentrations $(1 \times \mathrm{MIC}$ and $2 \times \mathrm{MIC})$ of RF3 was detected by flow cytometry.
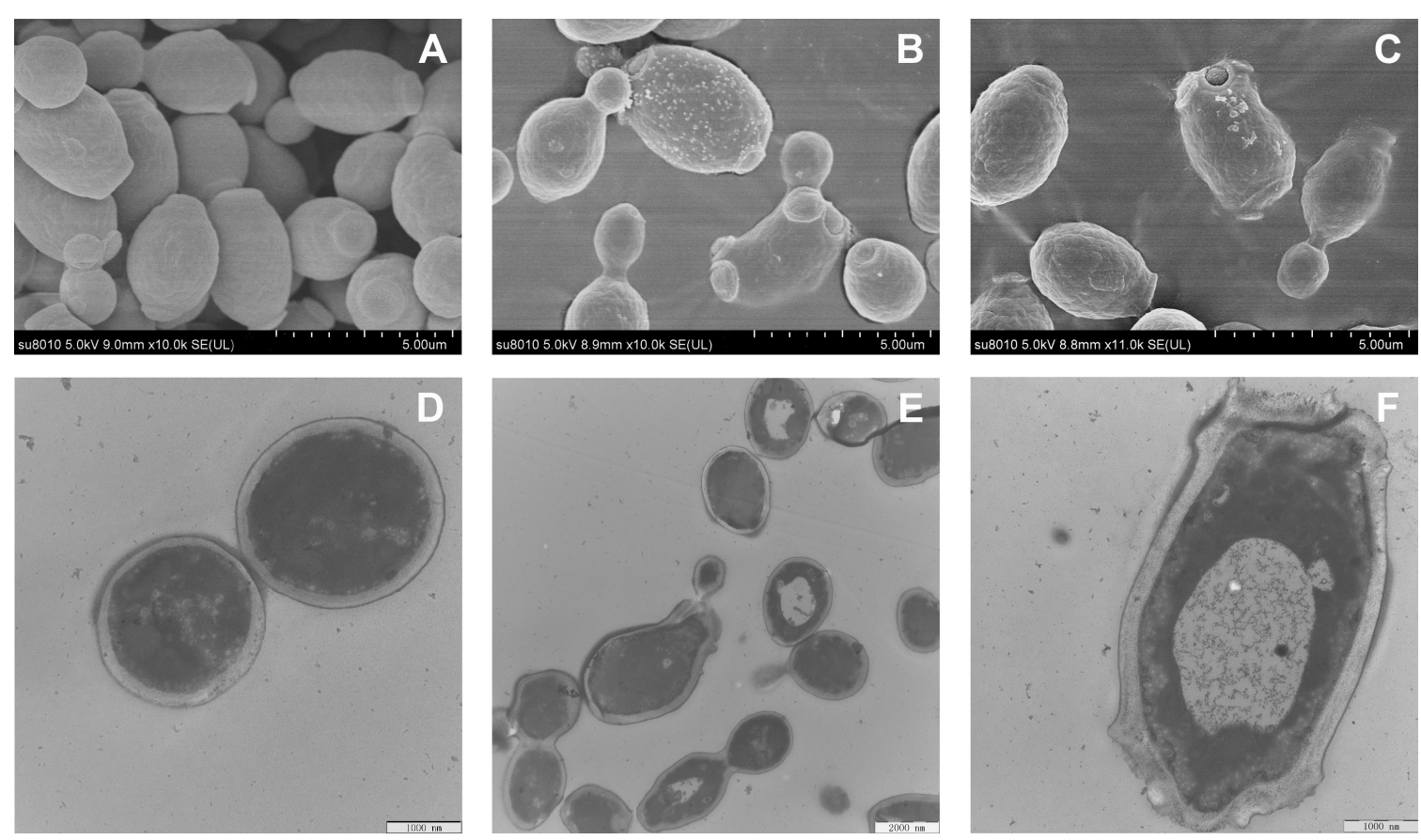

FIGURE 8 | Morphological changes in RF3-treated C. albicans cgmcc 2.2086. Scanning electron microscope (SEM) micrographs of C. albicans: (A) control, without peptide; (B,C) RF3 at $1 \times$ MIC. Transmission electron microscope (TEM) micrographs of C. albicans: (D) control, without peptide; (E,F) RF3 at $1 \times$ MIC.

backbone that result in $\alpha$-helical structures can be enhanced by increasing the chain length (Wiradharma et al., 2011). In comparison with Val-containing peptides, KV3 and RV3 peptides with Phe as the hydrophobic residue (KF3 and RF3) had lower helical contents (39.89 and 43.33\%) (Table 2). This observation was in agreement with a previous finding that Phe residues are less conducive for helical formation. Differences in helical contents between peptides containing different hydrophobic amino acids arise from the intrinsic helix-forming properties of the amino acids. The propensity of Val toward the helical structure is larger than that of Phe and Trp (Blaber et al., 1993). However, Trp residues did not have that much influence on the helical content. One possible explanation is that the structure of a peptide is not only determined by the intrinsic properties of a single residue; the contact between amino acid residues are also determinants of the final conformation.

Increasing the chain length resulted in enhanced $\alpha$-helical structures and increased net charges. The net amount is the most important characteristic of AMPs. The first step in antimicrobial actions is the electrostatic interactions between peptides and microbial membranes. The fungal cell wall is composed of glucan-chitin complexes and mannoproteins. Most of the mannoproteins carry N-linked glycans that have outer chains consisting of $\alpha$-linked mannose units. Phosphorylation of the mannosyl side chains contribute to the negative charges of fungal walls (Lipke and Ovalle, 1998). Large fractions of the negatively charged phosphatidylinositol are also found in fungi (van der Weerden et al., 2013). Higher cationic 


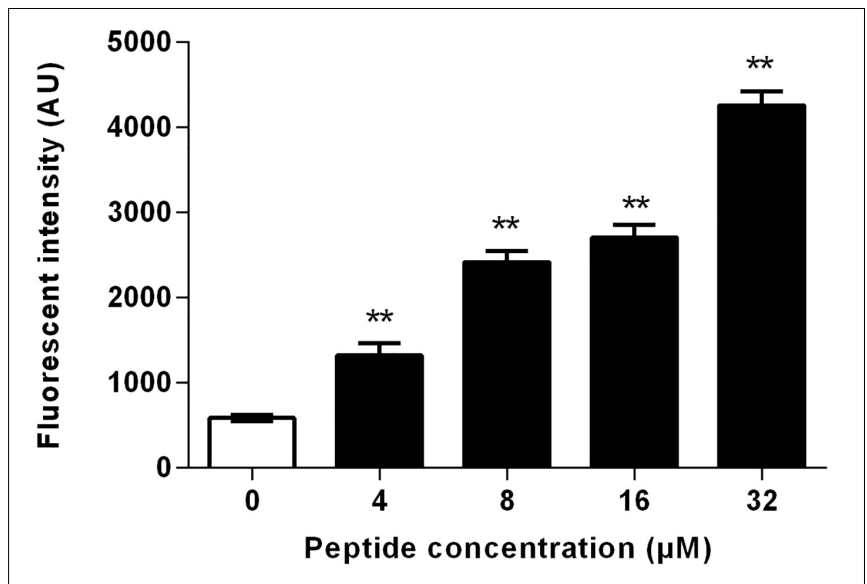

FIGURE 9 | Effect of RF3 on intracellular reactive oxygen species (ROS) formation of $C$. albicans cgmcc 2.2086. Cells were treated with RF3 (4-32 $\mu \mathrm{M})$ for $60 \mathrm{~min}$, and the level of ROS was measured using $2^{\prime}, 7^{\prime}$-dichlorofluorescein diacetate (DCFH-DA). ${ }^{* *} p<0.01$ (two-tailed Student's $t$-test) compared with control. Values are means $\pm \mathrm{SD}, n=3$.

charges enhance electrostatic interactions between peptides and negatively charged fungal membranes. The propensity toward helical structures causes a great membrane binding affinity. Enhancement of the properties, as mentioned earlier, improve the antimicrobial activities of AMPs. In this study, the 12 amino acid residue peptides, KV2 (with five net charges), was ineffective against all fungal strains, whereas the 18 amino acid residue peptides, KV3 (with seven net charges), exhibited slightly high antifungal activities (Table 3 ). The antifungal activities of these peptides were also improved by altering their amino acid compositions. Substituting Lys with Arg residues increased the antifungal activity of KV3 (Table 3 ). The guanidinium group of Arg has more dispersed positive charges than the single amine of Lys. This property enhances peptide-membrane electrostatic interactions that result in improved antimicrobial activities (Liu et al., 2007; Yang et al., 2019). Aromatic residues play an essential role in peptide membrane anchoring abilities (Marsh et al., 2007). Aromatic amino acid replacement altered the hydrophobicity of peptides. Hydrophobicity is important in antimicrobial activities of the peptides, as it facilitates peptide-membrane interactions and governs the extent of AMP insertions into the cell membrane (Chen et al., 2007). In the present study, peptides containing aromatic amino acid residues exhibited higher hydrophobicity than the Valcontaining peptides. Tryptophan-containing peptides (KW3 and RW3) exhibited the highest hydrophobicity (Table 1). This phenomenon was due to the high intrinsic hydrophobicity of Trp than that of Phe (Damodaran, 2008). Antifungal activities of aromatic amino acid-containing peptides were enhanced by improving their hydrophobic properties. KW3, RF3, and RW3, respectively, displayed 9-, 7-, and 14-fold antifungal activities on Candida sp. compared with the parent peptide, KV3 (Table 4). Interestingly, RV3 and KV3 did not exhibit good antifungal activities, although they possessed a strong $\alpha$-helical signature (Tables 2,3). The importance of hydrophobicity in the interactions of RV3 and KV3 with fungal membranes was, therefore, greater than the helical structural conformation.

Toxicity tests of new therapeutic compounds are essential in drug development. As shown in Figures 2, 3, the toxic effects of these peptides increased with increasing hydrophobicity. Increased hydrophobicity allows the depth of insertion of the peptides into microbial membranes, and deep penetration into the hydrophobic interiors of mammalian cells is enhanced by increased hydrophobicity. This increased antimicrobial activities and toxicity (Jiang et al., 2008). At a concentration of $64 \mu \mathrm{M}$, the cytotoxic effects of RF3 were observed, and cell selectivity properties of RF3 were lost (Figure 3). The therapeutic indices were calculated by determining the ratio of hemolytic activity to the antifungal activity. RF3 displayed strong cell selectivity properties toward C. albicans over human erythrocytes, as indicated by the highest TI value of 18.93 (Table 4). RF3 was screened and its fungicidal mechanisms determined.

Most $\alpha$-helical antifungal peptides exert antifungal activities by interfering with membrane permeability. The presence of negatively charged phosphatidylinositol in fungi makes the cytoplasmic membrane highly electronegative. This leads to the promotion in the strength of electrostatic interactions between the membrane and cation-bearing peptides. We report that RF3 depolarized cytoplasmic membranes in a concentrationdependent manner (Figure 6). This result indicates that the dissipation of membrane potential might be involved in channel or pore formation, thereby allowing the passage of ions or large molecules and thus leading to cytoplasmic membrane dysfunction and cell death (Te Winkel et al., 2016). The PI uptake assay also supported the changes in membrane permeability and integrity induced by RF3. PI, a membraneimpermeable dye, was used to detect cells that had permeable membranes. PI enters into cells and binds to nucleic acids and fluoresces red (Choi and Lee, 2014). RF3 treatment significantly increased membrane permeability (Figure 7). Fractured cell membranes and vesicular cytoplasm were observed after RF3 treatment (Figure 8). These results confirmed that RF3 exerted antifungal activities by disrupting membrane integrity. Compared with other kinds of novel antifungal agents that are designed base on the structure of FLU (Fakhim et al., 2017), this non-specific physical membrane-disrupting mechanism of RF3 reduced the development of antifungal resistance. Studies indicate that ROS production is involved in antifungal mechanisms of certain peptides. For example, the human salivary peptide histatin 5 has been shown to inhibit C. albicans by inducing the formation of ROS (Helmerhorst et al., 2001). Also, the fungicidal activity of protonectin, an AMP isolated from the venom of the neotropical social wasp Agelaia pallipes pallipes, is associated with the accumulation of ROS (Wang et al., 2015). Levels of ROS influence the proliferation and differentiation of fungal organisms (Belozerskaya and Gessler, 2007). However, excessive ROS production due to environmental stress causes hyperoxidation leading to the loss of cell functions and cell death (Gessler et al., 2007). Intracellular ROS generation was significantly increased by RF3 treatment (Figure 9). 


\section{CONCLUSION}

In conclusion, peptides with better hydrophobic properties exhibited greater antifungal activities. However, enhanced hydrophobicity also led to higher toxicity. Optimization of hydrophobicity is essential for cell selectivity. Among the designed peptides, RF3 exhibited the best cell selectivity and antifungal activity, specifically against FLU-resistant clinical C. albicans isolates. The dual-targeted antifungal mechanism of RF3 reported earlier reduced the probability of resistant development in fungi. These findings provide new insights into designs of antifungal peptides as alternative treatment options. Clearly, in vivo studies are required to elucidate the efficacy of RF3 in treating fungal infections fully. The mode of administration and pharmacokinetics also need further studies.

\section{DATA AVAILABILITY STATEMENT}

The raw data supporting the conclusions of this article will be made available by the authors, without undue reservation, to any qualified researcher.

\section{ETHICS STATEMENT}

The experimental protocol was reviewed and approved by the Ethics Committee of the Northeast Agriculture University Hospital, and the experimental method was carried out in

\section{REFERENCES}

Andes, D. R., Safdar, N., Baddley, J. W., Alexander, B., Brumble, L., Freifeld, A., et al. (2016). The epidemiology and outcomes of invasive Candida infections among organ transplant recipients in the United States: results of the Transplant-Associated Infection Surveillance Network (TRANSNET). Transpl. Infect. Dis. 18, 921-931. doi: 10.1111/tid.12613

Belozerskaya, T. A., and Gessler, N. N. (2007). Reactive oxygen species and the strategy of antioxidant defense in fungi: a review. Appl. Biochem. Microbiol. 43, 506-515. doi: 10.1134/S0003683807050031

Berkow, E. L., and Lockhart, S. R. (2017). Fluconazole resistance in Candida species: a current perspective. Infect. Drug Resist. 10, 237-245. doi: 10.2147/IDR. S118892

Bhetariya, P. J., Sharma, N., Singh, P., Tripathi, P., Upadhyay, S. K., and Gautam, P. (2017). "Human fungal pathogens and drug resistance against azole drugs," in The Drug Resistance in Bacteria, Fungi, Malaria, and Cancer, eds G. Arora, A. Sajid, and V. Kalia (Cham: Springer), 387-428. doi: 10.1007/978-3-319-486833_18

Blaber, M., Zhang, X. J., and Matthews, B. W. (1993). Structural basis of amino acid $\alpha$ helix propensity. Science 260, 1637-1640. doi: 10.1126/science.8503008

Broekaert, W. F., Terras, F., Cammue, B., and Osborn, R. W. (1995). Plant defensins: novel antimicrobial peptides as components of the host defense system. Plant Physiol. 108, 1353-1358. doi: 10.1104/pp.108.4.1353

Chen, Y., Guarnieri, M. T., Vasil, A. I., Vasil, M. L., Mant, C. T., and Hodges, R. S. (2007). Role of peptide hydrophobicity in the mechanism of action of $\alpha$-helical antimicrobial peptides. Antimicrob. Agents Chemother. 51, 1398-1406.

Choi, H., and Lee, D. G. (2014). Antifungal activity and pore-forming mechanism of astacidin 1 against Candida albicans. Biochimie 105, 58-63. doi: 10.1016/j. biochi.2014.06.014

Chou, S., Shao, C., Wang, J., Shan, A., Xu, L., Dong, N., et al. (2016). Short, multiple-stranded $\beta$-hairpin peptides have antimicrobial potency with high accordance with the approved guidelines and regulations. The participant provided her written informed consent to participate in this study.

\section{AUTHOR CONTRIBUTIONS}

YY and AS designed and conceived the experiments. YY, CW, and NG conducted the main experiments assay. LZ and YL analyzed the data. YY wrote the main manuscript text. SZ, JW, and AS supervised the work and revised the final version of the article. All authors contributed to the article and approved the submitted version.

\section{FUNDING}

This work was supported by the National Natural Science Foundation of China (31672434, 31472104, and 31872368); the Agriculture Research System of China (CARS-35); and the Natural Science Foundation of Heilongjiang Province (TD2019C001).

\section{SUPPLEMENTARY MATERIAL}

The Supplementary Material for this article can be found online at: https://www.frontiersin.org/articles/10.3389/fmicb. 2020.548620/full\#supplementary-material

selectivity and salt resistance. Acta Biomater. 30, 78-93. doi: 10.1016/j.actbio. 2015.11.002

Chou, S., Wang, J., Shang, L., Akhtar, M. U., Wang, Z., Shi, B., et al. (2019). Short, symmetric-helical peptides have narrow-spectrum activity with low resistance potential and high selectivity. Biomater. Sci. 7, 2394-2409. doi: 10. 1039/C9BM00044E

Ciociola, T., Giovati, L., Conti, S., Magliani, W., Santinoli, C., and Polonelli, L. (2016). Natural and synthetic peptides with antifungal activity. Future Med. Chem. 8, 1413-1433. doi: 10.4155/fmc-2016-0035

Damodaran, S. (2008). Amino Acids, Peptides and Proteins. Boca Raton, FL: CRC Press.

Dou, X., Gao, N., Lan, J., Han, J., Yang, Y., and Shan, A. (2019). TLR2/EGFR are two sensors for $\mathrm{pBD} 3$ and $\mathrm{pEP} 2 \mathrm{C}$ induction by sodium butyrate independent of HDAC inhibition. J. Agric. Food Chem. 68, 512-522. doi: 10.1021/acs.jafc. 9 b06569

Fakhim, H., Emami, S., Vaezi, A., Hashemi, S. M., Faeli, L., Diba, K., et al. (2017). In vitro activities of novel azole compounds ATTAF-1 and ATTAF-2 against fluconazole-susceptible and-resistant isolates of Candida species. Antimicrob. Agents Chemother. 61:e01106-16. doi: 10.1128/AAC.01106-16

Fesharaki, S. H., Haghani, I., Mousavi, B., Kargar, M. L., Boroumand, M., Anvari, M. S., et al. (2013). Endocarditis due to a co-infection of Candida albicans and Candida tropicalis in a drug abuser. J. Med. Microbiol. 62, 1763-1767. doi: 10.1099/jmm.0.060954-0

Fisher, M. C., Hawkins, N. J., Sanglard, D., and Gurr, S. J. (2018). Worldwide emergence of resistance to antifungal drugs challenges human health and food security. Science 360, 739-742. doi: 10.1126/science.aap7999

Ganz, T., and Lehrer, R. I. (1998). Antimicrobial peptides of vertebrates. Curr. Opin. Immunol. 10, 41-44.

Gessler, N. N., Aver'yanov, A. A., and Belozerskaya, T. A. (2007). Reactive oxygen species in regulation of fungal development. Biochemistry 72, 1091-1109. doi: $10.1134 /$ S0006297907100070 
Guilhelmelli, F., Vilela, N., Smidt, K. S., de Oliveira, M. A., da Cunha, Morales, et al. (2016). Activity of scorpion venom-derived antifungal peptides against planktonic cells of Candida spp. and Cryptococcus neoformans and Candida albicans biofilms. Front. Microbiol. 7:1844. doi: 10.3389/fmicb.2016.01844

Harioudh, M. K., Sahai, R., Mitra, K., and Ghosh, J. K. (2017). A short noncytotoxic antimicrobial peptide designed from A $\beta 29-40$ adopts nanostructure and shows in vivo anti-endotoxin activity. Chem. Commun. 53, 13079-13082. doi: 10.1039/C7CC07547B

Helmerhorst, E. J., Troxler, R. F., and Oppenheim, F. G. (2001). The human salivary peptide histatin 5 exerts its antifungal activity through the formation of reactive oxygen species. Proc. Natl. Acad. Sci. U.S.A. 98, 14637-14642. doi: $10.1073 /$ pnas. 141366998

Jiang, Z., Kullberg, B. J., Van Der Lee, H., Vasil, A. I., Hale, J. D., Mant, C. T., et al. (2008). Effects of hydrophobicity on the antifungal activity of $\alpha$-helical antimicrobial peptides. Chem. Biol. Drug Des. 72, 483-495. doi: 10.1111/j.17470285.2008.00728.x

Kodedová, M., and Sychrová, H. (2017). Synthetic antimicrobial peptides of the halictines family disturb the membrane integrity of Candida cells. Biochim. Biophys. Acta Biomembr. 1859, 1851-1858. doi: 10.1016/j.bbamem.2017. 06.005

Koehbach, J., and Craik, D. J. (2019). The vast structural diversity of antimicrobial peptides. Trends Pharmacol. Sci. 40, 517-528. doi: 10.1016/j.tips.2019.04.012

Lacerda, A. F., Pelegrini, P. B., de Oliveira, D. M., Vasconcelos, É. A., and Grossi-deSá, M. F. (2016). Anti-parasitic peptides from arthropods and their application in drug therapy. Front. Microbiol. 7:91. doi: 10.3389/fmicb.2016.00091

Lam, S. J., O’Brien-Simpson, N. M., Pantarat, N., Sulistio, A., Wong, E. H., Chen, Y.-Y., et al. (2016). Combating multidrug-resistant Gram-negative bacteria with structurally nanoengineered antimicrobial peptide polymers. Nat. Microbiol. 1:16162. doi: 10.1038/nmicrobiol.2016.162

Le, C.-F., Fang, C.-M., and Sekaran, S. D. (2017). Intracellular targeting mechanisms by antimicrobial peptides. Antimicrob. Agents Chemother. 61:e02340-16.

Lécorché, P., Walrant, A., Burlina, F., Dutot, L., Sagan, S., Mallet, J.-M., et al. (2012). Cellular uptake and biophysical properties of galactose and/or tryptophan containing cell-penetrating peptides. Biochim. Biophys. Acta Biomembr. 1818, 448-457. doi: 10.1016/j.bbamem.2011.12.003

Li, J., Koh, J.-J., Liu, S., Lakshminarayanan, R., Verma, C. S., and Beuerman, R. W. (2017). Membrane active antimicrobial peptides: translating mechanistic insights to design. Front. Neurosci. 11:73. doi: 10.3389/fnins.2017.00073

Li, L., Sun, J., Xia, S., Tian, X., Cheserek, M. J., and Le, G. (2016). Mechanism of antifungal activity of antimicrobial peptide APP, a cell-penetrating peptide derivative, against Candida albicans: intracellular DNA binding and cell cycle arrest. Appl. Microbiol. Biotechnol. 100, 3245-3253. doi: 10.1007/s00253-0157265-y

Limper, A. H., Adenis, A., Le, T., and Harrison, T. S. (2017). Fungal infections in HIV/AIDS. Lancet Infect. Dis. 17, e334-e343.

Lipke, P. N., and Ovalle, R. (1998). Cell wall architecture in yeast: new structure and new challenges. J. Bacteriol. 180, 3735-3740. doi: 10.1128/JB.180.15.37353740.1998

Liu, Z., Brady, A., Young, A., Rasimick, B., Chen, K., Zhou, C., et al. (2007). Length effects in antimicrobial peptides of the (RW) n series. Antimicrob. Agents Chemother. 51, 597-603.

Louis-Jeune, C., Andrade-Navarro, M. A., and Perez-Iratxeta, C. (2012). Prediction of protein secondary structure from circular dichroism using theoretically derived spectra. Proteins 80, 374-381. doi: 10.1002/prot.23188

Lum, K. Y., Tay, S. T., Le, C. F., Lee, V. S., Sabri, N. H., Velayuthan, R. D., et al. (2015). Activity of novel synthetic peptides against Candida albicans. Sci. Rep. 5:9657. doi: 10.1038/srep09657

Lupetti, A., Paulusma-Annema, A., Senesi, S., Campa, M., van Dissel, J. T., and Nibbering, P. H. (2002). Internal thiols and reactive oxygen species in candidacidal activity exerted by an N-terminal peptide of human lactoferrin. Antimicrob. Agents Chemother. 46, 1634-1639. doi: 10.1128/AAC.46.6.16341639.2002

Lv, Y., Wang, J., Gao, H., Wang, Z., Dong, N., Ma, Q., et al. (2014). Antimicrobial properties and membrane-active mechanism of a potential $\alpha$ helical antimicrobial derived from cathelicidin PMAP-36. PLoS One 9:e86364. doi: 10.1371/journal.pone.0086364
Lyu, Y., Chen, T., Shang, L., Yang, Y., Li, Z., Zhu, J., et al. (2019). Design of Trp-rich dodecapeptides with broad-spectrum antimicrobial potency and membrane-disruptive mechanism. J. Med. Chem. 62, 6941-6957. doi: 10.1021/ acs.jmedchem.9b00288

Marsh, D., Jost, M., Peggion, C., and Toniolo, C. (2007). Lipid chainlength dependence for incorporation of alamethicin in membranes: electron paramagnetic resonance studies on TOAC-spin labeled analogs. Biophys. J. 92, 4002-4011. doi: 10.1529/biophysj.107.104026

Methatham, T., Boonchuen, P., Jaree, P., Tassanakajon, A., and Somboonwiwat, K. (2017). Antiviral action of the antimicrobial peptide ALFPm3 from Penaeus monodon against white spot syndrome virus. Dev. Comp. Immunol. 69, 23-32. doi: 10.1016/j.dci.2016.11.023

Nett, J. E., and Andes, D. R. (2016). Antifungal agents: spectrum of activity, pharmacology, and clinical indications. Infect. Dis. Clin. 30, 51-83. doi: 10.1016/ j.idc.2015.10.012

Nguyen, L. T., Haney, E. F., and Vogel, H. J. (2011). The expanding scope of antimicrobial peptide structures and their modes of action. Trends Biotechnol. 29, 464-472. doi: 10.1016/j.tibtech.2011.05.001

Odds, F. C., Brown, A. J., and Gow, N. A. (2003). Antifungal agents: mechanisms of action. Trends Microbiol. 11, 272-279.

Pappas, P. G., Rex, J. H., Sobel, J. D., Filler, S. G., Dismukes, W. E., Walsh, T. J., et al. (2004). Guidelines for treatment of candidiasis. Clin. Infect. Dis. 38, 161-189. doi: $10.1086 / 380796$

Qi, X., Zhou, C., Li, P., Xu, W., Cao, Y., Ling, H., et al. (2010). Novel short antibacterial and antifungal peptides with low cytotoxicity: efficacy and action mechanisms. Biochem. Biophys. Res. Commun. 398, 594-600. doi: 10.1016/j. bbrc.2010.06.131

Sanglard, D. (2016). Emerging threats in antifungal-resistant fungal pathogens. Front. Med. 3:11. doi: 10.3389/fmed.2016.00011

Shao, C., Tian, H., Wang, T., Wang, Z., Chou, S., Shan, A., et al. (2018). Central $\beta$ turn increases the cell selectivity of imperfectly amphipathic $\alpha$-helical peptides. Acta Biomater. 69, 243-255. doi: 10.1016/j.actbio.2018.01.009

Te Winkel, J. D., Gray, D. A., Seistrup, K. H., Hamoen, L. W., and Strahl, H. (2016). Analysis of antimicrobial-triggered membrane depolarization using voltage sensitive dyes. Front. Cell. Dev. Biol. 4:29. doi: 10.3389/fcell.2016. 00029

van der Weerden, N. L., Bleackley, M. R., and Anderson, M. A. (2013). Properties and mechanisms of action of naturally occurring antifungal peptides. Cell. Mol. Life Sci. 70, 3545-3570.

Vazquez, J. A. (2017). Combination antifungal therapy: the new frontier. Future Microbiol. 2, 115-139. doi: 10.2217/17460913.2.2.115

Vos, W. M., Kuipers, O. P., Meer, J. R., and Siezen, R. J. (1995). Maturation pathway of nisin and other lantibiotics: post-translationally modified antimicrobial peptides exported by Gram-positive bacteria. Mol. Microbiol. 17, 427-437. doi: 10.1111/j.1365-2958.1995.mmi_17030427.x

Wang, J., Chou, S., Yang, Z., Yang, Y., Wang, Z., Song, J., et al. (2018). Combating drug-resistant fungi with novel imperfectly amphipathic palindromic peptides. J. Med. Chem. 61, 3889-3907. doi: 10.1021/acs.jmedchem.7b 01729

Wang, J., Dou, X., Song, J., Lyu, Y., Zhu, X., Xu, L., et al. (2019). Antimicrobial peptides: promising alternatives in the post feeding antibiotic era. Med. Res. Rev. 39, 831-859. doi: 10.1002/med.21542

Wang, K., Dang, W., Xie, J., Zhu, R., Sun, M., Jia, F., et al. (2015). Antimicrobial peptide protonectin disturbs the membrane integrity and induces ROS production in yeast cells. Biochim. Biophys. Acta Biomembr. 1848, 2365-2373. doi: 10.1016/j.bbamem.2015.07.008

Whaley, S. G., Berkow, E. L., Rybak, J. M., Nishimoto, A. T., Barker, K. S., and Rogers, P. D. (2016). Azole antifungal resistance in Candida albicans and emerging non-albicans Candida species. Front. Microbiol. 7:2173. doi: 10.3389/ fmicb.2016.02173

Williams, H., Campbell, L., Crompton, R. A., Singh, G., McHugh, B. J., Davidson, D. J., et al. (2018). Microbial host interactions and impaired wound healing in mice and humans: defining a role for BD14 and NOD2. J. Invest. Dermatol. 138, 2264-2274. doi: 10.1016/j.jid.2018.04.014

Wiradharma, N., Khoe, U., Hauser, C. A., Seow, S. V., Zhang, S., and Yang, Y.Y. (2011). Synthetic cationic amphiphilic $\alpha$-helical peptides as antimicrobial agents. Biomaterials 32, 2204-2212. doi: 10.1016/j.biomaterials.2010.11.054 
Wiradharma, N., Sng, M. Y., Khan, M., Ong, Z. Y., and Yang, Y. Y. (2013). Rationally designed $\alpha$-helical broad-spectrum antimicrobial peptides with idealized facial amphiphilicity. Macromol. Rapid Commun. 34, 74-80. doi: 10. 1002/marc.201200534

Wu, H., Liu, S., Wiradharma, N., Ong, Z. Y., Li, Y., Yang, Y. Y., et al. (2017). Short synthetic $\alpha$-helical-forming peptide amphiphiles for fungal keratitis treatment in vivo. Adv. Healthc. Mater. 6:1600777. doi: 10.1002/adhm.201600777

Wu, H., Ong, Z. Y., Liu, S., Li, Y., Wiradharma, N., Yang, Y. Y., et al. (2015). Synthetic $\beta$-sheet forming peptide amphiphiles for treatment of fungal keratitis. Biomaterials 43, 44-49. doi: 10.1016/j.biomaterials.2014.11.052

Yang, Y., Wu, D., Wang, C., Shan, A., Bi, C., Li, Y., et al. (2020). Hybridization with insect cecropin A (1-8) improve the stability and selectivity of naturally occurring peptides. Int. J. Mol. Sci. 21:1470. doi: 10.3390/ijms210 41470

Yang, Z., He, S., Wang, J., Yang, Y., Zhang, L., Li, Y., et al. (2019). Rational design of short peptide variants by using Kunitzin-RE, an amphibian-derived bioactivity peptide, for acquired potent broad-spectrum antimicrobial and improved therapeutic potential of commensalism coinfection of pathogens. J. Med. Chem. 62, 4586-4605. doi: 10.1021/acs.jmed-chem.9b00149
Zhang, L., Tong, Y., Dai, H., Cui, J., and Ren, B. (2015). Synergistic combinations of antifungals and antivirulence agents to fight against Candida albicans. Virulence 6, 362-371. doi: 10.1080/21505594.2015.1039885

Zhu, X., Zhang, L., Wang, J., Ma, Z., Xu, W., Li, J., et al. (2015). Characterization of antimicrobial activity and mechanisms of low amphipathic peptides with different $\alpha$-helical propensity. Acta Biomater. 18, 155-167. doi: 10.1016/j.actbio.2015.02.023

Conflict of Interest: The authors declare that the research was conducted in the absence of any commercial or financial relationships that could be construed as a potential conflict of interest.

Copyright (c) 2020 Yang, Wang, Gao, Lyu, Zhang, Zhang, Wang and Shan. This is an open-access article distributed under the terms of the Creative Commons Attribution License (CC BY). The use, distribution or reproduction in other forums is permitted, provided the original author(s) and the copyright owner(s) are credited and that the original publication in this journal is cited, in accordance with accepted academic practice. No use, distribution or reproduction is permitted which does not comply with these terms. 